\title{
INFLUENCE OF HOMOGENIZATION OF CLAY BATCH FOR LABORATORY TEST ON THE STRUCTURE OF THE CERAMIC SAMPLES
}

\author{
Nikita Toropkov ${ }^{1, *}$, Alexander Abakumov ${ }^{1}$ \\ ${ }^{1}$ Tomsk Polytechnic University, Lenin av. 30, Tomsk, 634050, Russia
}

\begin{abstract}
In this paper, we study the chemical and mineralogical composition of the Krasnoyarsk Kray clay used in the production of coarse ceramics. It is found that the fire -strength depends of method of preparation of clay paste. It is shown that the forced dissolution of the raw clay material effectively homogenizes clay paste. As a result, strength of the samples increased during firing. It is also justified by the influence of their mineralogical composition and there method of the preparation. It is proved that conditions of preparation and mineralogical composition affect equally.
\end{abstract}

\section{Introduction}

Batch preparation is an important technological step in the production of ceramic construction materials, which significantly determine the stability of the parameters of technological processes at the stages of forming, drying and firing.

Changes in moisture, mineralogical and fractional composition of batch lead to variability in product quality $[1,2]$. Therefore, one way to improve the quality of the product is to optimize characteristics of batch raw material with respect to homogeneity criteria. Homogeneity of batch composition can be achieved at the stages of dosing, and during processing of clay paste by department of mass-preparation and forming $[1,3]$.

Special attention should be paid to the technological methods of humidity correction of clay paste, which determine average moisture content of the total volume of batch $[4,5]$. The technological effect is a change of rheological properties of clay -water system, according to the amount of correction additives and the method of their distribution due to the batch volume. In addition, interaction of water and dispersed particles of a solid phase plays a specific role [6]. The technological properties of the clay-water system depends on the amount and the method of mechanical processing, thermal regime during mass processing, as well as the time course of physical and chemical processes of water and particles of a dispersed solid phase [7].

Thus, batch of the same composition may represent different technological parameters depending on the particular implementation of mass processing [8]. The objectives of this study are to determine the effect of different methods of mass processing on the final

* Corresponding author: zerogooff@gmail.com 
properties of samples of coarse ceramics in laboratory testing [3, 9]. One of the tasks of laboratory research is to produce prototypes

Based on the results it is possible to determine not only the e ways to improve quality of the final product by varying the mass processing, but also the feasibility of introducing additional operations into the existing technological schemes.

\section{Materials and methods}

Investigation of properties of clay raw materials was carried out on three types of clay loam, which is typical for clay deposits in Krasnoyarsk Kray. GL1 is an average sample of low-melting red-burning clay, GL2 and GL3 are average samples of Kantatsky deposits: fireproof and refractory clay, respectively. These clay deposits are used as a basic raw material component in the current production of ceramic wall products in accordance with the GOST 530-2012. The properties of clay raw materials are shown in Table 1.

Table 1. Characteristics of clay raw materials of Krasnoyarsk Kray

\begin{tabular}{|l|l|l|l|l|}
\hline Index & Types & Plasticity & $\begin{array}{l}\text { Grain size distribution } \\
\text { by Rutkowski }\end{array}$ & $\begin{array}{l}\text { Smallest } \\
\text { capillary } \\
\text { moisture }\end{array}$ \\
\hline GL1 & $\begin{array}{l}\text { Red-burning, } \\
\text { fusible }\end{array}$ & $\begin{array}{l}\text { moderately } \\
\text { plastic }\end{array}$ & Clay loam & $12,1 \%$ \\
\hline GL2 & $\begin{array}{l}\text { White-burning, } \\
\text { fireproof }\end{array}$ & $\begin{array}{l}\text { moderately } \\
\text { plastic }\end{array}$ & Clay loam & $12,7 \%$ \\
\hline GL3 & $\begin{array}{l}\text { White-burning, } \\
\text { refractory }\end{array}$ & $\begin{array}{l}\text { moderately } \\
\text { plastic }\end{array}$ & Clay loam & $11,9 \%$ \\
\hline
\end{tabular}

Granulation composition was determined by the Rutkowski method [2]. The lowest capillary moisture was determined by the procedure of excess moisture extraction on a press at constant pressure [10].

Table 2 shows the chemical composition of the oxide raw clay determined by an electron microscope with analyzing attachment JEOL-9000. It should be noted that the electron microscopy data differ from those obtained by the other methods of analysis.

Table 2. Oxide chemical composition of clay raw materials of Krasnoyarsk Kray

\begin{tabular}{|l|l|l|l|}
\hline Oxide & GL1 & GL2 & GL3 \\
\hline $\mathrm{SiO}_{2}$ & $58,09 \%$ & $61,71 \%$ & $57,4 \%$ \\
\hline $\mathrm{Al}_{2} \mathrm{O}_{3}$ & $16,82 \%$ & $27,66 \%$ & $28,41 \%$ \\
\hline $\mathrm{Fe}_{2} \mathrm{O}_{3}$ & $11,92 \%$ & $5,33 \%$ & $7,58 \%$ \\
\hline $\mathrm{MgO}$ & $3,09 \%$ & $1,48 \%$ & $0,75 \%$ \\
\hline $\mathrm{CaO}$ & $6,25 \%$ & $2,15 \%$ & $1,28 \%$ \\
\hline $\mathrm{Na}_{2} \mathrm{O}$ & $1,44 \%$ & $0,02 \%$ & $0,33 \%$ \\
\hline $\mathrm{K}_{2} \mathrm{O}$ & $2,39 \%$ & $1,65 \%$ & $1,85 \%$ \\
\hline $\mathrm{TiO}_{2}$ & - & - & $2,39 \%$ \\
\hline
\end{tabular}

Also, X-ray analysis using a DRON-3M device was performed. The samples were irradiated with monochromatic Cu $\alpha$ radiation with a wavelength of $1.54056 \AA$ due to the following parameters: accelerating voltage $90 \mathrm{\kappa W}$, beam current $30 \mathrm{~mA}$, scanning angle range $10-80^{\circ}$, scanning step $0,03^{\circ}$, set signal time $1 \mathrm{~s}$. Synchronous thermal analysis was carried out on the STA 449 F3 Jupiter.

Clay raw materials samples were dried to the air humidity and crushed by a jaw crusher to an average particle size of $1 \mathrm{~mm}$ passing through a sieve of $1 \mathrm{~mm}$ mesh. The further sample preparation was a different way of plastic mass preparation. The first method was the implementation of a traditional method of mass preparation in a laboratory. 
$20 \%$ of water was added to the dry mixture of raw clay powder, and after stirring the mass was kept in a sealed container.

The second method involves forming an aqueous slurry by dispersing coarse suspension in a centrifugal homogenizer of BASKEY company. Dehydration to a residual moisture content of $20 \%$ was carried out in a centrifuge with membrane filters.

Table 3. Mixture compositions

\begin{tabular}{|l|l|l|l|}
\hline Index & Contents of GL1 & Contents of GL2 & Contents of GL3 \\
\hline 1 & $100 \%$ & - & - \\
\hline 2 & $85 \%$ & $15 \%$ & - \\
\hline 3 & $70 \%$ & $30 \%$ & - \\
\hline 4 & $50 \%$ & $50 \%$ & - \\
\hline 5 & $85 \%$ & - & $15 \%$ \\
\hline 6 & $70 \%$ & - & $30 \%$ \\
\hline 7 & $50 \%$ & - & $50 \%$ \\
\hline
\end{tabular}

\section{Results}

To predict raw clay material behaviour during drying and burning processes, it is necessary to know a compound composition shown in Figure 1.

As seen in Figure 1, all clay minerals consist of minerals, but GL -3 contains a large amount of montmorillonite and white feldspar, mainly represented by albite. The sample of GL -2 feldspar contains less quantity as shown in Table 2 and Figure 1, and more quantity of kaolinite, which explains its size distribution. The sample GL -1 is also represented mostly by kaolinite, quartz and albite. High content of ferric oxide gives red color (table 2). These assumptions are confirmed by synchronic analysis of three samples - figure 2, 3 and 4.

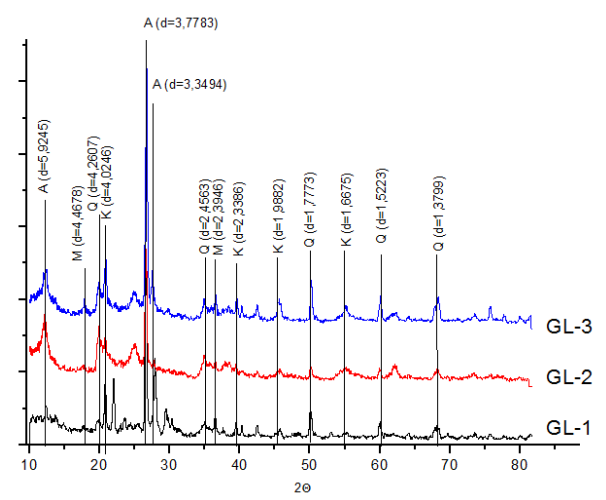

Fig. 1. X-ray pattern of Krasnoyarsk Kray clay used in the production of coarse ceramics. $\mathrm{K}-$

kaolinite, $\mathrm{M}$ - montmorillonite, $\mathrm{A}$ - albite, $\mathrm{Q}$ - quartz.

Endothermic effects observed in the temperature range of $20-200^{\circ} \mathrm{C}$ are accompanied by weight loss up to $5 \%$. It is mainly caused by loss of the adsorption and interlayer water due to clay minerals - hydromica and kaolinite. Exothermic effect in the range of $200-400^{\circ} \mathrm{C}$, accompanied by mass loss of $2.5 \%$ is connected to the processes of burning of fine organic impurities. Thermodestruction process of kaolinitic clay minerals occurs at low endothermic effect with a minimum at $455{ }^{\circ} \mathrm{C}$, and is accompanied by a weight loss of $2.5 \%$ in the temperature range of $400-$ $600{ }^{\circ} \mathrm{C}$.

High endothermic effect with a minimum at $700{ }^{\circ} \mathrm{C}$ and the weight loss of $3 \%$ in the temperature range of $600-800{ }^{\circ} \mathrm{C}$ is due to dehydration of hydromicaceous clay minerals. The negative heat effect above $890^{\circ} \mathrm{C}$ is caused by the silicate materials formation in the melt system. 
Post-firing compression strength of the molded test cubes with the $25 \times 25 \times 25 \mathrm{~mm}$ size of the raw material baked at a temperature of $850-1000{ }^{\circ} \mathrm{C}$ with the step of $50{ }^{\circ} \mathrm{C}$ was investigated to determine the effect of batch preparation on the basis of clay raw materials. $[3,10]$.

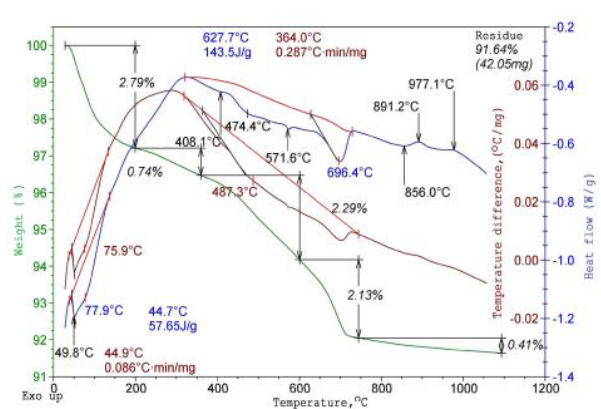

Fig. 2. DSC sample GL-1.

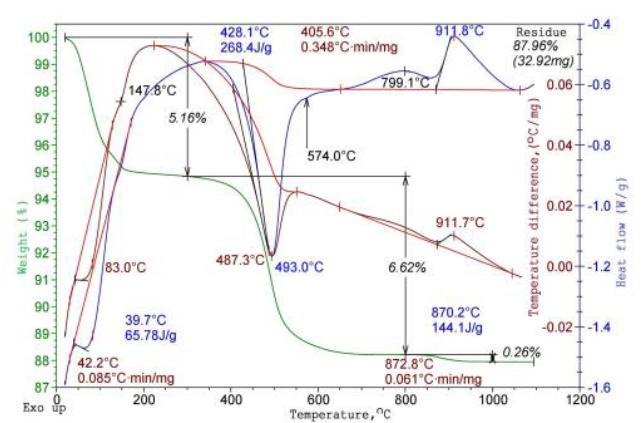

Fig. 3. DSC sample GL-2

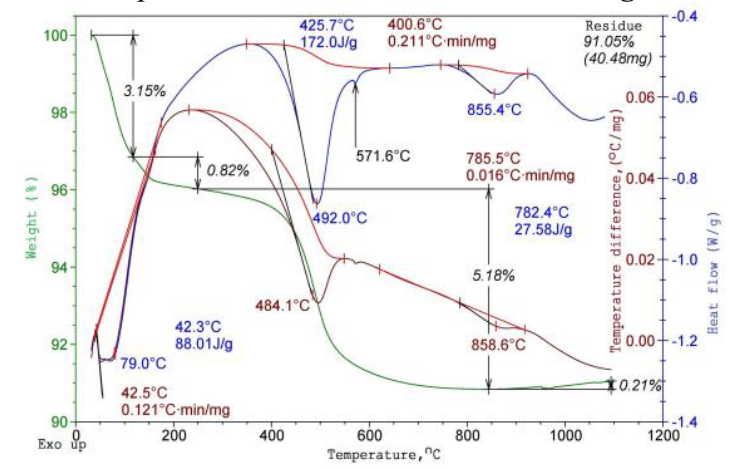

Fig. 4. DSC sample GL-3

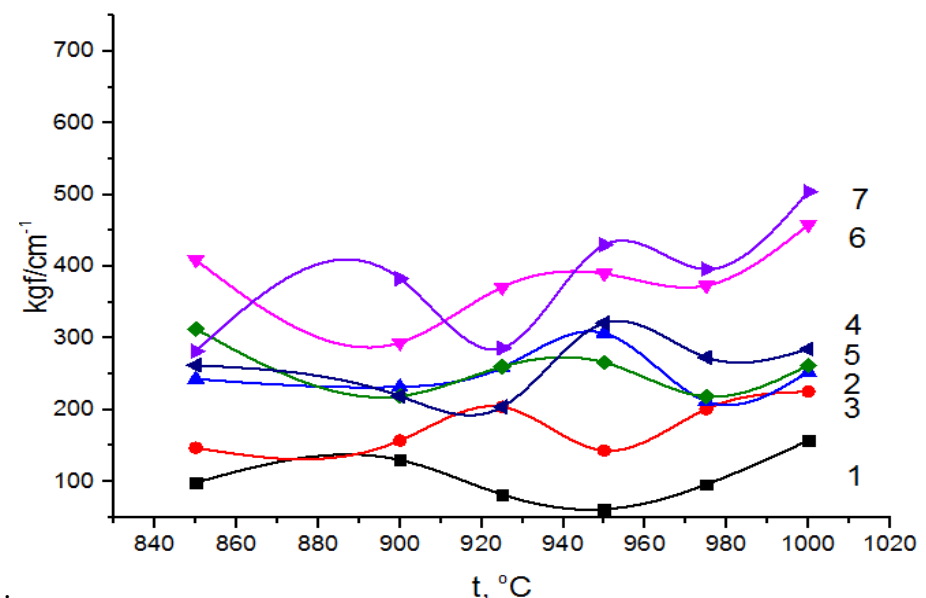

Figure 5. Dependence of the compressive strength of the final firing temperature for the samples prepared by method 1 prepared by the method 1 .

Comparing the graphs shown in Figure 5 and 6 it can be concluded that the moisture averaging by method 1 gives a strong fluctuation effect of the strength values and, consequently, the marks of bricks. This deviation is related to averaging the chemical composition of the material in the volume of the material. It is worth noting that the sample 1 is pure clay, and the same fluctuations of the strength are presented on the graph. Due to the graphs the forced dissolution of clay raw materials both in pure form and in a mixture gives the best strength values of the baked samples. According to the sample 4, the 
maximum strength reaches $508 \mathrm{kgf} / \mathrm{cm}^{2}$, while at the stock preparation of raw materials subjected to the centrifugal forced dissolution it reaches $609 \mathrm{kgf} / \mathrm{cm}^{2}$. The other samples have the same analogy.

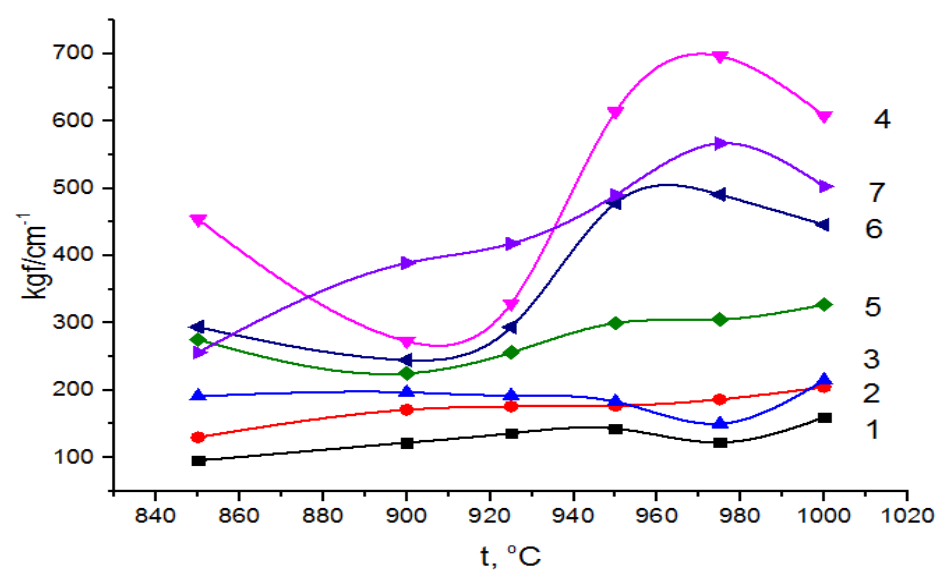

Figure 6. Dependence of the compressive strength of the final firing temperature for the samples prepared by method 2 .

These deviations were repeated on a series of 10 experiments. Apparently, it is due to the fact that at dissolution the clay particles have lower between each other, and at drying and further firing small conglomerates become more active to sinter. It explains high strength values of the samples obtained by the method 2 .

\section{Conclusion}

The aim of the work was to study changes of the technological properties of the batch depending on the composition and mass preparation. It was shown that the forced dissolution of raw clay materials in the centrifugal mixer provides a smaller variance in laboratory tests. It is discovered that the final properties of the ceramic body depended not only on the composition of the batch, but also the method of forming and mass processing.

\section{References}

1. T. Vakalova, V. Pogrebenkov Refractories and Industrial Ceramics 5017 (2009)

2. G. Cultrone, E. Sebastián, I. Sidraba Applied Clay Science 28297 (2005)

3. V. Lotov Glass and Ceramics 57164 (1999)

4. V. Lotov Bulletin of the Tomsk Polytechnic University 31177 (2007)

5. V. Pogrebenkov, K. Kostikov Advanced Materials Research 1040367 (2014)

6. A. Stolboushkin, A. Ivanov, O. Fomina, A. Fomin, G. Storozhenko, Advanced Materials and Structural Engineering Proceedings of the International Conference on Advanced Materials and Engineering Structural Technology 87 (2015)

7. G. Ogandzhanyan, D. Ogandzhanyan Theoretical \& Applied Science 5 (25) 144 (2015)

8. A. Tatarin, R. Vogt Ziegelindustrie International/Brick and Tile Industry International 420 (2013)

9. N. Dhami, M. Reddy, A. Mukherjee Ecological Engineering 3931 (2012)

10. V. Lotov Glass and Ceramics 55123 (1998 